\title{
Notas etnográficas sobre a educação em valores no contexto escolar
}

\section{RESUMO}

Este artigo objetiva identificar, analisar e dar visibilidade às práticas de educação em valores desenvolvidas nos espaços intraescolares, com ênfase no papel atribuído à Educação Física neste desígnio conjuntural. Para tanto realizamos um estudo de caso em uma escola da rede pública do município de Vitória/ES, reconhecida por desenvolver um trabalho significativo na localidade em que está inserida. Os instrumentos de coleta de dados constituíram-se a partir de um conjunto de observações e entrevistas semiestruturadas. Os resultados demonstraram que a Educação Física é considerada como sendo potencialmente eficaz para o engendramento de práticas de educação em valores, sobretudo, em decorrência do clima afetivo empreendido nos seus espaços pedagógicos. Assim, conclui-se que é fundamental tornar exequível tal propósito educativo em toda a escola, pautando-se, para tanto, numa prática testemunhal.

PALAVRAS-CHAVE: Educação em valores; Contexto escolar; Educação física
Adriano Lopes de Souza

Doutor em Educação Física - Universidade

Federal do Espírito Santo Universidade Federal do Tocantins, Tocantinópolis, Tocantins, Brasil. adriano.lopes@mail.uft.edu.br ๑ $\underline{\text { https://orcid.org/0000-0002-7036-573X }}$

Otávio Tavares Doutor em Educação Física - Universidade Gama Filho Universidade Federal do Espírito Santo, Vitória, Espírito Santo, Brasil tavaresotavio@yahoo.com.br ○ https://orcid.org/0000-0002-5893-4311 


\title{
Ethnographic notes on education in values in the school context
}

\begin{abstract}
This article aims to identify, analyze and make visible the educational practices in values that are developed in intra-school spaces, with emphasis on the role attributed to Physical Education in this conjuncture. To do this, we conducted a case study in a public school in the city of Vitória/ES, recognized for carrying out important work in the place where it is located. Data collection consisted of a set of observations and semi-structured interviews. The results showed that Physical Education is considered potentially effective to engender educational practices in values, above all, due to the affective climate that develops in its pedagogical spaces. Thus, it is concluded that it is essential to make such an educational purpose feasible in the whole school, based on a testimonial practice.
\end{abstract}

KEYWORDS: Education in values; School context; Physical education

\section{Notas etnográficas sobre la educación en valores en la escuela}

\section{RESUMEN}

Este artículo objetiva identificar, analizar y dar visibilidad a las prácticas de educación en valores desarrollados en los espacios intraescolares, con énfasis en el papel atribuido a la Educación Física en este propósito coyuntural. Para ello realizamos un estudio de caso en una escuela de la red pública del municipio de Vitória/ES, reconocida por desarrollar un trabajo significativo en el lugar donde se ubica. Los instrumentos de recolección de datos consistieron en un conjunto de observaciones y entrevistas semiestructuradas. Los resultados demostraron que la Educación Física es considerada como potencialmente eficaz para el engendramiento de prácticas de educación en valores, sobre todo, en consecuencia del clima afectivo emprendido en sus espacios pedagógicos. Así, se concluye que es fundamental hacer factible tal propósito educativo en toda la escuela, pautándose, para tanto, en una práctica testimonial.

PALABRAS-CLAVE: Educación en valores; Escuela; Educación física 


\section{INTRODUÇÃO}

O mundo não é. O mundo está sendo. Como subjetividade curiosa, inteligente, interferidora na objetividade com que dialeticamente me relaciono, meu papel no mundo não é só o de quem constata o que ocorre mas também o de quem intervém como sujeito de ocorrências. Não sou apenas objeto da História, mas seu sujeito igualmente (FREIRE, 1996, p. 30).

Concordamos com a afirmativa de Paulo Freire na epígrafe acima, visto que o mundo que temos hoje resulta das ações realizadas ao longo da história, e, consequentemente, o mundo que teremos no futuro será resultado das intervenções protagonizadas por nós no tempo presente. Este tempo, aliás, tem sido marcado por uma pluralidade de valores, entendidos como "crise de valores" - marcada por um desaparecimento progressivo dos valores morais - ou, ainda, como "valores em crise" - marcado por uma transformação e/ou rearranjo dos valores considerados tradicionais (LA TAILLE; MENIN, 2009).

Com efeito, estamos diante do surgimento de uma demanda de invidualização, na qual a ideia do interesse comum vem perdendo o seu valor prático, enfraquecendo os relacionamentos pessoais e profissionais (BASSO; TAVARES, 2012). Tal cenário é reflexo do que Bauman (2007) denomina de "vida líquida", isto é, fluida, instável, vivida em condições de constante incerteza. Essa sociedade flexível e pulverizada tem feito com que os indivíduos busquem a plena realização do Eu, por meio de uma ética permissiva e hedonista, na qual o que parece estar em voga não é mais o esforço, o civismo ou a disciplina, mas, o culto aos próprios desejos e à sua realização imediata em detrimento do bem comum (LIPOVETSKY, 2005).

Não obstante, é justamente nessa realidade cada vez mais complexa e instável que a educação precisa ser pensada e orquestrada, sobretudo, a educação em valores ${ }^{1}$ - equivalente ao que Coll et al. (2000) classificam como dimensão atitudinal ${ }^{2}$-, devendo encontrar na instituição escolar, um terreno fértil para a promoção e socialização de normas, valores e atitudes considerados importantes para a formação de um sujeito autônomo, apto para exercer a sua cidadania. Afinal, os

\footnotetext{
1 Tipo de educação que visa alcançar o maior número de espaços e participantes escolares, explicitando, discutindo e reconstruindo regras, valores e princípios que orientem uma convivência justa e harmoniosa, a partir de procedimentos democráticos e estratégias que privilegiem a construção de um perfil de aluno autônomo e apto para exercer a sua cidadania (MENIN; BATAGLIA; ZECHI, 2013).

${ }^{2}$ Segundo Coll et al. (2000) os conteúdos de ensino classificam-se em três dimensões: conceitual, procedimental e atitudinal. A primeira é de natureza teórica e explicativa - conceitos e fatos (POZO, 2000); a segunda, possui um viés mais prático - habilidades, técnicas, estratégias etc. (COLL; VALLS, 2000); enquanto a terceira envolve os componentes cognitivo, afetivo e comportamental - normas, atitudes e valores (SARABIA, 2000).
} 
problemas que têm assolado a sociedade contemporânea não demandam uma solução exclusivamente técnico-científica, mas, precisam ser acompanhados de uma reorientação ética dos princípios que as regulam (PUIG, 1998). Nesse contexto, compreendemos que a Educação Física (EF), por exemplo, possui um papel social de contribuir para forjar o desenvolvimento de potencialidades humanas dos educandos a partir do espectro de práticas corporais disponíveis, sobrepujando, destarte, o ensino de fundamentos e de técnicas (SOUZA; TAVARES, 2019).

Portanto, diante do exposto, compreende-se que observar/vivenciar o funcionamento da lógica de uma realidade escolar específica é condição necessária para compreender com maior profundidade os desdobramentos da dimensão atitudinal em um determinado espaço educativo. Não obstante, vale destacar que a estrutura desta investigação não comporta a intenção de julgar se determinada escola, incluindo os seus métodos e os valores que desenvolve, são bons ou ruins. Em lugar disso, buscamos nos apropriar de algumas variáveis contextuais que permeiam os aspectos valorativos neste âmbito, priorizando o nosso olhar para os espaços destinados à Educação Física.

Diante do exposto, o presente estudo emerge com o objetivo de identificar, analisar e dar visibilidade às práticas de educação em valores - dimensão atitudinal - desenvolvidas nos espaços intraescolares, dando centralidade ao papel atribuído à EF neste desígnio conjuntural.

\section{CAMINHAR METODOLÓGICO}

A presente investigação foi aprovada pelo Comitê de Ética em Pesquisa (CEP), sob o parecer de número 1.145.371. Trata-se de um estudo de caso de inspiração etnográfica em uma escola da rede pública do município de Vitória/ES, visando engendrar uma análise interpretativa desta unidade social, compreendendo-a no contexto das suas particularidades (GOLDENBERG, 2004). Para tanto, utilizamos um delineamento qualitativo descritivo, com um conjunto de técnicas centradas em procedimentos hermenêuticos, na tentativa de descrever e interpretar as relações e os significados que determinado grupo social dá à sua experiência cotidiana (MOLINA NETO, 2004).

A escolha da referida escola foi feita a partir da indicação por parte da Secretaria de Educação (Seme) do município de Vitória-ES a respeito de algumas escolas que fossem consideradas referências em práticas de "educação em valores" (MENIN; BATAGLIA; ZECHI, 2013). A partir daí, realizamos uma “aproximação preliminar” (MOLINA, 2004) nas respectivas 
escolas, o que permitiu-nos optar por aquela que apresentou melhor receptividade e facilidade de acesso: a Escola Municipal de Ensino Fundamental (EMEF) Andara Luther da Silva (ALS) ${ }^{3}$.

Por conseguinte, estabelecemos algumas pautas como referência para ir materializando aquilo que, de fato, queríamos averiguar nas nossas observações, em consonância com os objetivos do presente estudo, são elas: 1- Relacionamento interpessoal dos sujeitos escolares (professores, alunos e demais funcionários); 2 - Atitude dos sujeitos escolares diante dos conflitos surgidos; 3Atividades realizadas para trabalhar aspectos atitudinais.

Conforme aponta Machado (2002), toda pesquisa de campo (e, por extensão, toda observação) tem um caráter "participante", visto que, mesmo quando o estudo não visa uma intervenção direta em um determinado grupo ou instituição, invariavelmente, estamos compartilhando um jogo de relações a partir das interações estabelecidas entre pesquisador-pesquisado. Não obstante, ainda que sejam classificadas como sendo "participante", ressalta-se que as observações desenvolvidas no referido cenário educativo, visaram um baixo nível de interferência nas atividades cotidianas.

Ao todo, permanecemos no campo durante aproximadamente 4 meses, realizando inicialmente dois dias de observação por semana, em horários diversificados, visto que a escola funciona em tempo integral. Com efeito, em consonância com a nossa organização e disponibilidade de horário, fomos aumentando gradativamente não apenas a quantidade de carga horária no interior da escola, mas a qualidade da nossa presença. Afinal, fomos encontrando uma espécie de justa medida a respeito da melhor forma de nos posicionarmos.

Isto posto, durante o referido recorte temporal foram realizadas diversas observações registradas em um diário de campo - a respeito das intrincadas e complexas rede de relações intraescolares. Tais observações incluíram diferentes espaços escolares, tais como: corredores, pátio, quadra, auditório, sala dos professores, sala de informática, diretoria, coordenação, refeitório, e, em especial, as aulas de EF.

Além das observações, também foi realizado um conjunto de entrevistas semiestruturadas e conversas informais com diferentes sujeitos escolares - da portaria à diretoria -, em decorrência da notoriedade que estes demonstraram na organização do tempo, dos espaços e das atividades no

\footnotetext{
${ }^{3}$ A opção de utilizar um nome fictício para a escola e para todos os sujeitos que dela fazem parte, foi tomada com o intuito de preservar o anonimato dos mesmos. Localizada em um bairro periférico, a referida escola atende predominantemente crianças e jovens da comunidade em que está inserida, ofertando o Ensino Fundamental I e II ( $1^{\circ}$ ao $5^{\circ}$ ano e $6^{\circ}$ ao $9^{\circ}$ ano, respectivamente) nos turnos matutino e vespertino e também na modalidade "educação em tempo integral.
} 
tocante à dinâmica pedagógica da escola. Para tanto, tomou-se como ponto de partida um roteiro previamente definido de sete perguntas, com pautas relativas a diferentes aspectos, como por exemplo, as funções que lhe são atribuídas na escola, a percepção a respeito da disciplina de Educação Física e os valores priorizados naquele âmbito educativo. Ademais, ressalta-se que a opção pelas entrevistas semiestruturadas nos permitiu a flexibilidade necessária para poder explorar alguns aspectos não previstos a priori (NEGRINE, 2004).

Aliado a tais técnicas, também consultamos o Projeto Político Pedagógico (PPP) da EMEF ALS, no intuito de identificar valores, normas e atitudes prescritos neste documento. Segundo, Sá-Silva, Almeida e Guidani (2009), o uso de documentos como fonte de dados de uma pesquisa se faz pertinente na medida em que estes proporcionam uma riqueza de informações que ampliam o entendimento de objetos cuja compreensão necessita de uma maior contextualização.

Com efeito, em face do entendimento de que o principal instrumento de coleta e análise de dados de um estudo desse tipo é o próprio pesquisador, propomo-nos a expor com minúcias as principais nuances identificadas durante a nossa jornada naquilo que pode ser chamado liricamente de "chão da escola", conforme veremos a seguir.

\section{ADENTRANDO E VIVENCIANDO O "CHÃO DA ESCOLA": um campo de tensões, acordos e reconstruções}

O momento de inserção no campo costuma ser algo tão importante, quanto complexo em uma pesquisa, visto que o pesquisador estará adentrando em um espaço social do qual ele não faz parte. Por isso, lograr êxito nesta etapa inicial depende, em grande medida, da boa aceitação dos respectivos sujeitos que o compõem. Nesse cenário, é fundamental que o pesquisador direcione seus esforços para a criação de uma atmosfera empática, conquistando o acesso para transitar livremente pelos espaços que são os seus, aliado à disponibilidade dos sujeitos pesquisados para colaborarem com aquilo que lhes fosse solicitado.

Com efeito, uma pessoa em especial acabou constituindo-se como um "informante-chave"4 neste período crítico: trata-se de uma das pedagogas da instituição: a Marta, com a qual, aliás, desde a primeira conversa começara a ser desenvolvida uma empatia mútua. Na ocasião, ela se emocionou

\footnotetext{
${ }^{4}$ Membro que possui um notável respeito e conhecimento da cultura estudada, o qual é capaz de compreender o papel desempenhado pelo pesquisador enquanto um aprendiz cultural. Ver mais em: SPRADLEY, J.P. The ethnographic interview. New York, Holt, Rinehart and Winston, 1979.
} 
bastante ao falar sobre a necessidade de investirmos em uma educação em valores, confidenciando-nos, tanto os transtornos que a referida escola havia enfrentado num passado não muito distante - incluindo, a ocorrência de alguns casos policiais -, quanto os avanços que haviam sido alcançados até aquele momento.

Portanto, o que a priori, deveria ser apenas um breve momento para sondar algumas questões mais pontuais que interessassem ao estudo, acabou se estendendo por quase duas horas de conversa e reflexão conjunta, retratando uma espécie de desabafo de uma profissional que simplesmente demonstrava um enorme comprometimento com aquele universo do qual ela fazia parte, há mais de 10 anos, convivendo com uma dinamicidade de ocorrências e inúmeros desdobramentos cotidianos. Seguramente, a natureza deste primeiro contato foi fundamental para começarmos a estabelecer uma relação promissora e mútua de apoio e confiança.

Foi a Marta, inclusive, a responsável por intermediar os encontros com os demais profissionais da escola, dentre eles, a diretora e os professores, em especial, aqueles que ministram a disciplina de $\mathrm{EF}^{5}$, possibilitando-nos esclarecer alguns pontos importantes da pesquisa (objetivos, procedimentos etc.). Em suma, tanto a direção quanto o corpo docente reconheceram a pertinência do presente estudo naquele contexto educativo, dando o aval para o início das nossas observações.

Assim, iniciamos as observações em uma sexta-feira, aproximadamente às 10:00 horas da manhã. Logo ao adentrar na escola, nos deparamos com uma quase inexistente movimentação de pessoas por ali. Fomos informados na portaria de que os estudantes, juntamente com alguns professores, estavam na quadra, situada no pátio da escola. Então, munidos de ansiedade e curiosidade, nos dirigimos até lá.

O dia estava levemente ensolarado, e os alunos, por sua vez, estavam dispostos (sentados) em fileiras na quadra e outros na arquibancada, enquanto os professores estavam em pé, de frente para eles. A primeira impressão que tivemos é de que poderia estar havendo algum tipo de gincana. Mas, dentro de alguns minutos, notamos as fileiras sendo retiradas daquele local, uma de cada vez, puxadas por um determinado professor. Ao encontrarmos o professor Tony, fomos informados de que tratava-se de um procedimento rotineiro da escola, uma vez que, nos momentos de intervalo todas as turmas eram direcionadas para a quadra e, quando tocava o horário, retornavam para as suas salas sob a supervisão do respectivo professor.

\footnotetext{
${ }^{5}$ A EMEF ALS possui dois professores de EF, os quais chamaremos de Tony e Cida, ambos formados na UFES em 1990 e 1991, respectivamente.
} 
Desde os primeiros dias, identificamos que - como uma via de mão dupla - nós também éramos um alvo potencial de observações, julgamentos e expectativas por parte dos membros daquele local. Afinal, para eles, éramos um "corpo estranho" que acabara de adentrar no seu pequeno e complexo universo. Algo marcante (e esperado), neste período, foram as recorrentes aproximações de alguns estudantes, sobretudo, as crianças, que, após lançarem olhares curiosos/desconfiados, questionavam quem éramos e o que fazíamos ali. Aliás, logo notamos que a nossa presença em alguns espaços da escola era um dos fatores que concorria para alterar (inflamar ou constranger) o comportamento dos sujeitos observados, especialmente, dos estudantes, que, não raras vezes, pareciam querer chamar a atenção para si, ao falar mais alto, ao se pendurar na trave ou no alambrado ou, ainda, ao esbarrar propositalmente nos colegas, requisitando uma intervenção do professor.

Ora, sem a pretensão de sustentar que tais exemplos não faziam parte do dia-a-dia da escola, identificamos que tais atitudes - reincidentes por parte de alguns alunos - eram acompanhadas por olhares direcionados para os profissionais da escola e em seguida para nós. De fato, questões dessa natureza já foram comentadas por Goldenberg (2004, p. 55):

O pesquisador interfere nas respostas do grupo ou indivíduo que pesquisa. A melhor maneira de controlar esta interferência é tendo consciência de como sua presença afeta o grupo e até que ponto este fato pode ser minimizado ou, inclusive, analisado como dado da pesquisa.

Isto posto, desde o início das observações, algumas questões referentes à melhor forma de nos posicionarmos diante dos fenômenos e dos atores sociais, começaram a tensionar a necessidade de mobilizarmos algumas estratégias a fim de, por um lado, desobstruir alguns bloqueios e, por outro, minimizar a agitação exagerada, até o ponto em que não comprometesse mais a espontaneidade dos mesmos. Coisas como essa foram exigindo-nos um cuidado maior nas nossas entradas, andanças e saídas dos espaços escolares.

Inicialmente, por exemplo, as anotações no diário de campo eram feitas concomitantemente com as observações, a fim de aumentar a precisão das informações obtidas. Todavia, ao perceber um certo desconforto por parte de alguns sujeitos observados (tanto docentes, como discentes), optamos por fazê-las em um momento posterior, minimizando, assim, uma possível sensação de estarem sendo alvo de julgamentos.

Tal mudança na forma de registrar os dados parece ter surtido um efeito positivo no sentido de estreitar os laços com os respectivos sujeitos, uma vez que estes se sentiram mais dispostos a 
aceitarem e, até mesmo, buscarem uma maior interação, resultando em relevantes informações a respeito dos fenômenos ocorridos. Por outro lado, para não prejudicar uma descrição densa sobre a ocorrência dos mesmos, nos encarregamos de fazer os registros escritos imediatamente após a retirada daquele local.

Em nossas observações, identificamos que a portaria (composta por uma porteira e um vigilante), representava não apenas a entrada e saída dos sujeitos escolares, mas, a oportunidade de também coletarmos informações pertinentes para a pesquisa. Certo dia, por exemplo, estabelecemos um diálogo com um dos vigilantes - o João - a respeito de questões disciplinares na EMEF ALS. Este nos confidenciou fatos que já aconteceram no seu interior e, em especial, no seu entorno, quase sempre associados à questão das drogas. Segundo ele, diferentemente de anos anteriores em que houveram casos de drogas dentro da escola, naquele ano, por sua vez, tal problemática parecia estar sob controle, pelo menos nas suas dependências, em virtude de um conjunto de ações realizadas pela escola em parceria com a polícia civil, promovendo palestras e debates junto aos alunos.

Com o tempo, notamos que aqueles olhares curiosos e desconfiados por parte dos discentes foram sendo substituídos por olhares de confiança e contentamento a cada novo encontro. Nesta etapa, o pesquisador já estava sendo chamado de "tio" pelos alunos menores e de "professor" pelos maiores. Ambos passaram a procurá-lo na hora do intervalo para brincar ou simplesmente para conversar, chegando a cobrar seu comparecimento nas suas respectivas atividades escolares, tais como: "você não vai para o passeio com a gente?" - a EMEF ALS sempre buscava proporcionar visitas extraescolares em teatros, clubes, museus etc. Numa certa sexta-feira, algumas crianças desavisadas chegaram a questionar se o pesquisador voltaria à escola no dia seguinte, ao passo que este respondeu com semblante de espanto: “mas, amanhã é sábado!”, causando uma série de risos entre elas.

Em suma, apesar de toda a complexidade que envolve a lógica escolar, tal imersão neste campo de tensões, acordos e reconstruções possibilitou-nos identificar uma certa regularidade na dinâmica da escola, com determinados elementos de caráter atitudinal, nos quais destaca-se o engendramento de relações interpessoais de respeito, parceria e cumplicidade entre os membros que a compõem, incluindo a relação com os alunos e, em especial, à tríade direção-coordenação-professorado. Tal constatação é corroborada nas entrevistas com diferentes sujeitos escolares ao serem questionados sobre o que consideravam como principais pontos positivos da escola, conforme os seguintes relatos: 
"Eu vejo a união dos profissionais mesmo. Por exemplo, quando está dando problema mais sério na sala, ele [o aluno] não vai ser mandado para a coordenação e depois vai ser mandado de volta para sala e o professor vai perder o respeito dele [...]. Existe todo um trabalho para pegar esse aluno, ligar para os pais, fazer uma ocorrência, mas não fica impune. A gente tem uma grande cumplicidade na escola" (Carla - Professora-Assistente de Educação Especial).

"Essa questão do respeito ao próximo. Nós avançamos muito nessa questão!" (Lúcia-Coordenadora de turno).

Nesse contexto, um outro aspecto atitudinal significativo observado na EMEF ALS - e que mantém estreita relação com o anterior -, tanto nas falas como nas interações entre os membros desta instituição, é a valorização da democracia e da igualdade nas relações interpessoais, como pode ser percebido na seguinte narrativa:

\begin{abstract}
"Uma coisa que eu vejo aqui e que é fundamental e não vejo em outras escolas é que esta escola é muito democrática. Todas as decisões tomadas de maneira muito democrática, desde a diretora, a coordenadora, a pedagoga. Até os pais e a comunidade escolar participam efetivamente das decisões do projeto da escola" (Beto - Professor de Geografia).
\end{abstract}

Nesse contexto, cabe-nos ressaltar que a diretora da EMEF ALS foi escolhida a partir de uma votação da própria comunidade escolar, incluindo os pais dos alunos, devido ao trabalho que a mesma já desenvolvia naquele âmbito - conforme relatado pelo corpo docente da escola. Ora, este acesso a tal cargo por intermédio de uma eleição contextualizada parece-nos deveras pertinente porque vai de encontro às seleções nada transparentes que não raras vezes recaem nas escolas públicas, tal como nos adverte Oliveira e Carvalho (2018).

De acordo com Pedro-Silva (2013), a conscientização da própria comunidade sobre o fato de que a instituição escolar é pública e de que lhe pertence, passa necessariamente por essa democratização das relações escolares, isto é, pela mudança do tipo de relação interindividual estabelecida, que costuma ser de coação. Ora, tal valorização dos princípios democráticos na EMEF ALS, também foi identificada no seu PPP, vinculando-se à formação e vivência da cidadania.

A seguir, para fins analíticos, enfocaremos um dos momentos-chave considerados potenciais para o desenvolvimento de um tipo de educação em valores nesta instituição: Trata-se das aulas de EF, envolvendo os professores desta disciplina e os alunos da escola.

\title{
As aulas de EF
}


A partir das observações e dos diálogos estabelecidos com diferentes sujeitos escolares, foi possível constatar um ponto significativo sobre esta disciplina: ela é considerada por uma grande parte da comunidade escolar como a "queridinha" da escola. E, de fato, ao perguntarmos se estes sujeitos identificavam algum tipo de preferência por parte dos alunos em relação a alguma disciplina na escola, nos chamou a atenção, a forma enfática com que tal questão foi respondida.

"Com certeza! (risos) Eles amam a EF! [...] Se você fizer um teste aqui, raramente o aluno vai falar outra disciplina. Tanto que a aula que eles não admitem que seja suspensa é essa. Acho que até abririam mão de sair mais cedo para ficar na aula de EF. Quando a gente pensa em algum trabalho, uma palestra, alguma coisa, se a gente faz na aula de EF, eles reclamam. Você pode fazer em qualquer aula, mas, em EF, não" (Marta-Pedagoga).

"Com certeza! Por eu ser uma professora auxiliar que faz um trabalho colaborativo, eu acabo caindo em todas as áreas, acompanho um pouco de todas as disciplinas e normalmente os alunos de Educação Especial desta escola têm uma preferência pelas atividades de Arte e de EF" (Carla-Professora-auxiliar de Educação Especial).

“Ah! A EF, né? De manhã eu sou praticamente detestada e a tarde sou super amada (risos). Coordenador não tem como. Eles te veem de uma forma super diferente. É a mesma pessoa, mas, vista de formas bem diferentes" (Lúcia Coordenadora de turno ${ }^{6}$ ).

Nota-se, em tais falas, uma compreensão quase unânime acerca da popularidade da EF junto aos discentes da EMEF ALS. Vale ressaltar que este achado não consiste em um fenômeno exclusivo dessa escola. Afinal, tal como identificado em estudos anteriores (LOVISOLO, 1995; TAVARES et al., 1996; BETTI; LIZ, 2003) a EF parece ter um lugar privilegiado no gosto dos estudantes. Mas, e quanto aos professores desta disciplina, por sua vez, será que também compartilham este entendimento? Com a palavra, os professores de EF da escola:

"Sim! Com certeza! Isso aí, pra mim, é claro! [...] Você vê assim: quando o menino vai sair da sala, ele quer sair correndo pra EF. Quando ele vai retornar pra sala de aula [de outra disciplina], ele "faz hora", demora, enrola, fala que vai pro banheiro, que quer beber água, ele não quer voltar pra sala" (Tony Professor de EF).

"Percebo sim. Pela hora que eu chego na sala. Às vezes, eu fico até sem graça, porque eu chego para dar bom dia, querendo fazer eles entenderem que estão saindo de uma aula para entrar na minha, mas, na hora que eu "boto" o pé na porta da sala a empolgação é tanta, eles parecem uma "pipoquinha" pulando em

${ }^{6}$ A coordenadora Lúcia é formada em EF e ministra aula desta disciplina no turno vespertino. 
cima de mim. Aí eu tenho que acalmá-los, pra fazer a chamada, acertar os combinados sobre como vai ser a aula, mas, não dá pra você tirar isso né? Tem que deixar. Acho muito importante olhar nos olhos deles, tocar neles, deixar eles me tocarem. Essa troca faz toda a diferença. E ai eles vão se acalmando, vão sentando, e vamos conversando" (Cida-Professora de EF).

A partir dos enunciados acima, temos o indicativo de que muitos discentes, ao mesmo tempo em que apresentam uma inclinação favorável para a aula de EF, também parecem nutrir uma afetividade positiva em relação ao seu respectivo professor, fato que, aliás, se traduz em um importante elemento na formação de valores e atitudes dos alunos. Afinal, tal como pontua Sousa (2001, p. 21):

Os valores recebem grande poder energético dos afectos. Sendo os motivadores das atitudes e comportamentos das pessoas, recebem esta energia motivacional das dimensões afectivas da personalidade. A pessoa poderá ter um juízo cognitivo que a leva a uma dada atitude mas, quando de facto actua, a sua actuação pauta-se mais pela emoção e pelo sentimento do que pela lógica do raciocínio.

Nesta perspectiva, com o intuito de problematizarmos e refletirmos um pouco mais sobre esta questão, apresentamos o exemplo da experiência descrita por Santos (1998, p. 51):

Recordo-me, com saudade, dos tempos de escola. Lembro com que ansiedade aguardávamos pelo recreio. Naqueles poucos minutos podíamos ser crianças: brincávamos, jogávamos, tínhamos lazer, tínhamos prazer. Quando voltávamos para a aula, deixávamos do lado de fora da sala toda nossa vivacidade, alegria e descontração, pois aula era coisa séria. Por isso não se concebiam brincadeiras ou jogos na sala de aula, espaço reservado a atividades caracterizadas pela seriedade.

Com efeito, baseado no conjunto de observações realizadas na EMEF ALS, pode-se articular que a EF - longe de se equiparar ao momento do intervalo/recreio, tampouco de representar um espaço destituído de seriedade - talvez se diferencie de grande parte das disciplinas, justamente por ensejar maior espaço para elementos eminentemente lúdicos (inerentes àquele momento), podendo aproveitá-los, inclusive, como uma abertura para promover a aprendizagem, tal como argumentado por um dos professores da disciplina:

"[...] se o professor aproveita esse gosto, esse prazer com que aluno chega na aula, se ele lança uma coisa boa, prazerosa, ai você ganha qualquer coisa. Em virtude do ambiente, o professor fica mais acessivel, conversando com ele, mostrando o movimento, a possibilidade de troca é muito maior. É a oportunidade que você tem para introduzir conhecimento. [...] Os próprios conteúdos da EF favorecem: os jogos lúdicos, os esportes, as brincadeiras. Tudo isso chama mais a atenção do aluno e desperta a questão da afetividade e o prazer pela atividade" (Tony - Professor de EF). 
Estas premissas são também sustentadas por outros profissionais da escola, corroborando o entendimento de que, do ponto de vista afetivo, a EF se destaca em relação às demais disciplinas escolares, sob justificativas que transitam pela organização destas aulas e, sobretudo, pela questão do espaço destinado para a sua prática, conforme ilustrado nas seguintes narrativas:

"A EF tem um papel fundamental na escola porque tem legitimidade para desenvolver trabalhos pedagógicos fora da sala de aula. A proposta de desenvolvimento humano passa por esse desenvolvimento fisico e mental. Então as aulas de EF também melhoram o desempenho dos alunos nas outras disciplinas. [...] Todos os professores desejam ocupar aquele espaço" (Izabel-Diretora).

"Aqui na escola, o que eles mais gostam são as aulas mais livres, com mais liberdade e autonomia para a criação. Aquelas matérias em sala (português, matemática...) eles não têm essa liberdade de criação" (Carla Professora-Assistente de Educação Especial).

“[...] Essa coisa de ficar o tempo todo na sala sentado, satura. A sensação é de estar enclausurado num espaço fechado, em que a mente está encharcada de informações. O corpo deles está em transformação, né? Eles gostam de estar em atividade. Passa muito por aí. [...] Lá [na aula de EF] eles têm uma dinâmica de atividades diferentes, têm mais liberdade. Então, para o aluno, a EF é a aula que mais dá prazer" (Marta - Pedagoga).

Assim, identificamos nas falas destes e de outros sujeitos escolares uma argumentação que articula o clima afetivo desenvolvido nas aulas de EF com diferentes aprendizagens. Ora, a tese apresentada por eles de que a promoção de um ambiente mais atrativo, afetivo e prazeroso nas aulas influenciam positivamente na aprendizagem, encontra sustentação teórica nas concepções Piagetiana (apud LA TAILLE, 1992) e Walloniana (apud DANTAS, 1992), as quais acentuam o papel desempenhado pela afetividade no desenvolvimento da inteligência, uma vez que, na ausência da primeira, não haveria motivação e interesse para o aprimoramento da segunda [e aqui, estenderíamos também para as habilidades e atitudes]. Afinal, conforme sustenta Sarabia (2000, p. 137-138):

[...] o aluno desenvolverá atitudes positivas ou negativas em relação a determinadas matérias não somente em função do conteúdo de cada disciplina, mas também e de um modo inevitavelmente inter-relacionado, em função do ambiente que for gerado durante a aprendizagem desses conhecimentos e das possibilidades que surgirão ao realizar uma série de atividades e de mostrar um comportamento que seja aceitável para os outros. 
Por fim, cabe-nos assinalar que esse discurso que atribui uma potencialidade do trato da dimensão atitudinal nas aulas de EF também aparece no próprio PPP da EMEF ALS, ao conferir significativos aspectos atitudinais categorizados nesta disciplina, como por exemplo, um melhor convívio social por meio de suas práticas corporais.

\section{REFLEXÕES FINAIS}

Este estudo não se propôs a julgar se a referida escola, incluindo os seus métodos e os valores que desenvolve, são bons ou ruins, mas, buscou compreender os desdobramentos das práticas empreendidas em direção a um tipo de educação em valores no "chão da escola" e suas respectivas implicações nos sujeitos escolares. Assim, os resultados desta pesquisa, nos permitiram dar visibilidade para algumas dessas práticas potencialmente eficazes para o engendramento de relações interpessoais de respeito, parceria, igualdade e cumplicidade entre os membros que compõem a comunidade escolar.

Dentre os momentos-chave que colocaram em evidência tais elementos valorativos, enfocamos as aulas de EF. Constatamos a existência de um discurso que lhe atribui uma potencialidade para o desenvolvimento de conteúdos de natureza atitudinal, expresso tanto nas falas dos sujeitos, como no próprio projeto pedagógico da escola. As razões que sustentam essa tese perpassam, sobretudo, pelo clima afetivo empreendido nos seus espaços pedagógicos. Assim, conforme pontua Lovisolo (2002), a EF deve procurar fomentar a construção de sentimentos referentes à potência da vida no próprio corpo. Para ele, talvez, esta, seja a singularidade da área.

Todavia, é preciso ter presente que a educação em valores não deve restringir-se a apenas uma disciplina ou a um momento específico. Ao contrário, é responsabilidade de toda comunidade escolar, de modo que cada um dos seus membros possa servir como referenciais valorativos nos diferentes momentos em que o aluno estiver na escola.

Ademais, cumpre-nos ressaltar que a nossa escolha metodológica nos conferiu a impossibilidade de generalizarmos os resultados desse trabalho para além da realidade pesquisada, representando, portanto, sua principal limitação. Em contrapartida, este empreendimento investigativo nos reserva um horizonte de possibilidades para dialogarmos com outros universos escolares, a fim de verificar se os dados encontrados também se repetem em outros casos.

Por fim, a título de conclusão, importa-nos salientar que quanto maior for a harmonia de interesses, objetivos, valores e atitudes entre os referidos sujeitos na dinâmica da escola, tanto mais 
eficiente poderá ser orquestrar esse tipo de educação. Outrossim, quanto maior for a coerência entre aquilo que se pretende ensinar na escola com aquilo que, de fato, se vivencia neste ambiente, maior será a possibilidade de tornar exequível tal propósito educativo, pautando-se numa prática testemunhal, isto é, na corporeificação da palavra pelo exemplo, a qual, aliás, atravessa todo o discurso freireano.

\section{REFERÊNCIAS}

BASSO, Fabiano; TAVARES, Otávio. O Enquadramento Axiológico do Ensino dos Esportes: Problemas e Perspectivas. Revista da ALESDE, vol. 2, pp. 96-106, 2012.

BAUMAN, Zygmunt. Vida Líquida. Rio de Janeiro: Jorge Zahar, 2007.

BETTI, Mauro; LIZ, Marlene Terezinha Facco. Educação Física escolar: a perspectiva de alunas do ensino fundamental. Revista Motriz, Rio Claro, vol. 9, 2003, pp. 135-142.

BRASIL. Ministério da Educação. Conselho Nacional de Educação. Recreio como atividade escolar: Parecer $n^{\circ}$ 02/2003. Distrito Federal, 2003. Disponível em: http://portal.mec.gov.br/cne/arquivos/pdf/CEB002_2003.pdf. Acesso em: 23 de Julho de 2017.

COLL, César. et al. Os conteúdos na reforma. Porto Alegre: Artmed, 2000.

COLL, César; VALLS, Enric. A aprendizagem e o ensino de procedimentos. In: COLL, César. et al. (Org.). Os conteúdos na reforma: ensino e aprendizagem de conceitos, procedimentos e atitudes. Porto Alegre: Artmed, 2000, pp. 73-118.

CORTELLA, Mário Sérgio. Não se desespere!: provocações filosóficas. Petrópolis, RJ: Vozes, 2013.

DANTAS, Heloysa. A afetividade e a construção do sujeito na psicogenética de Wallon. In: LA TAILLE, Yves; OLIVEIRA, Marta Kohl; DANTAS, Heloysa. Piaget, Vygotsky, Wallon: teorias psicogenéticas em discussão. São Paulo: Summus, 1992.

FREIRE, Paulo. Pedagogia da Autonomia: saberes necessários à prática educativa. São Paulo: Paz e Terra. 1996.

FREITAS, Marcos César de; JACOB, Rosangela Nezeiro da Fonseca. Inclusão educacional de crianças com deficiências: notas do chão da escola. Educação e Pesquisa, São Paulo, v. 45, e186303, 2019. Disponível em http://dx.doi.org/10.1590/s1678-4634201945186303. Acesso em: 01 abr. 2019.

GOLDENBERG, Mirian. A arte de pesquisar: como fazer pesquisa qualitativa em Ciências Sociais. $8^{\circ}$ ed. Rio de Janeiro: Record, 2004.

LA TAILLE, Yves. Desenvolvimento do juízo moral e afetividade na teoria de Jean Piaget. In: LA TAILLE, Yves; OLIVEIRA, Marta Kohl; DANTAS, Heloysa. Piaget, Vygotsky, Wallon: teorias psicogenéticas em discussão. São Paulo: Summus, 1992. 
LA TAILLE, Yves.; MENIN, Maria Suzana de Stefano (org.). Crise de valores ou valores em crise? Porto Alegre: Artmed, 2009.

LIBÂNEO, José Carlos. Didática. São Paulo: Cortez, 1994.

LIMA, Lauro de Oliveira. Piaget Para Principiantes. 2a ed. São Paulo: Summus, 1980.

LIPOVETSKY, Gilles. A era do vazio: ensaios sobre o individualismo. São Paulo: Manole, 2005.

LOVISOLO, Hugo. Da educação física escolar: intelecto, emoção e corpo. Revista Motriz, Rio Claro, vol. 8, n.3, 2002, pp. 15-18.

LOVISOLO, Hugo. Educação Física: arte da mediação. Rio de Janeiro: Sprint, 1995.

MACHADO, Marília Novaes da Mata Machado. Entrevista de pesquisa: a interação pesquisador-entrevistado. Belo Horizonte: c/Arte, 2002.

MENIN, Maria Suzana de Stefano; BATAGLIA, Patricia Unger Raphael; ZECHI, Juliana Aparecida Matias Zechi (Org.). Projetos bem sucedidos de educação em valores: relatos de escolas públicas brasileiras. $1^{\text {a }}$ ed. São Paulo: Cortez, 2013.

MOLINA NETO, Vicente. Etnografia: uma opção metodológica para alguns problemas de investigação no âmbito da Educação Física. In: MOLINA NETO, Vicente.; TRIVIÑOS, Augusto Nibaldo Silva (Org.). A pesquisa qualitativa na Educação Física: alternativas metodológicas. Edição Revisada e Ampliada. $2^{\mathrm{a}}$ ed. Porto Alegre: Sulina, 2004, pp. 107-140.

MOLINA, Rosane Kreusburg. O enfoque teórico metodológico qualitativo e o estudo de caso: uma reflexão introdutória. In: MOLINA NETO, Vicente.; TRIVIÑOS, Augusto Nibaldo Silva (Org.). A pesquisa qualitativa na Educação Física: alternativas metodológicas. Edição Revisada e Ampliada. $2^{\mathrm{a}}$ ed. Porto Alegre: Sulina, vol. 1, 2004, p. 95-105.

NEGRINE, Airton. Instrumentos de coleta de informações na pesquisa qualitativa. In: MOLINA NETO, Vicente.; TRIVIÑOS, Augusto Nibaldo Silva (Org.). A pesquisa qualitativa na Educação Física:

alternativas metodológicas. Edição Revisada e Ampliada. $2^{\mathrm{a}}$ ed. Porto Alegre: Sulina, 2004, vol. 1, pp. 61-93.

OLIVEIRA, Ana Cristina Prado de; CARVALHO, Cynthia Paes de. Gestão escolar, liderança do diretor e resultados educacionais no Brasil. Revista Brasileira de Educação, Rio de Janeiro: ANPEd; Campinas: Autores Associados, v. 23, 2018.

PEDRO-SILVA, Nelson. Ética, (in)disciplina e relação professor-aluno. In: LA TAILLE, YVES; JUSTO, José Sterza; PEDRO-SILVA, Nelson. Indisciplina/Disciplina: ética, moral e ação do professor. $5^{\text {a }}$ ed. Porto Alegre: Mediação, 2013, pp. 69-120.

POZO, Juan Ignacio. A aprendizagem e o ensino de fatos e conceitos. In: COLL, César et al. (Org.). Os conteúdos na reforma: ensino e aprendizagem de conceitos, procedimentos e atitudes. Porto Alegre: Artmed, 2000, pp. 17-72.

PUIG, Josep Maria. Ética e valores: métodos para um ensino transversal. São Paulo: Casa do Psicólogo, 1998. 
SÁ-SILVA, Jackson Ronie; ALMEIDA Cristóvão Domingos; GUIDANI, Joel Felipe. Pesquisa documental: pistas teóricas e metodológicas. Revista Brasileira de História e Ciências Sociais, vol.1, n. 1, 2009, pp. $1-15$.

SANTOS, Carlos Antonio. Jogos e atividades lúdicas na alfabetização. Rio de Janeiro: Sprint, 1998.

SARABIA, Bernabé. A aprendizagem e o ensino das atitudes. In: COLL, César et al. (Org.). Os conteúdos na reforma: ensino e aprendizagem de conceitos, procedimentos e atitudes. Porto Alegre: Artmed, 2000, p. 119-178.

SOUSA, Alberto. Educação em valores: na Pré-escolaridade e no $1^{\circ}$ Ciclo do Ensino Básico. Lisboa: ESE João de Deus, 2001.

SOUZA, Adriano Lopes de; Tavares, Otávio. A percepção discente em relação às aprendizagens dos conteúdos atitudinais nas aulas de Educação Física escolar: um estudo de caso. Motrivivência, v. 31, p.

01-16, 2019.

TAVARES, Otávio. et al. Perfil das Preferências culturais e desportivas dos alunos do Colégio Pedro II - Rio de Janeiro. Artus - Revista de Educação Física e Desportos, vol. 12, n. 1, 1996, pp. 45-59.

NOTAS DE AUTOR

AGRADECIMENTOS - Não se aplica

CONTRIBUIÇÃO DE AUTORIA - Não se aplica.

FINANCIAMENTO - Não se aplica.

CONSENTIMENTO DE USO DE IMAGEM - Não se aplica.

APROVAÇÃO DE COMITÊ DE ÉTICA EM PESQUISA - Não se aplica.

CONFLITO DE INTERESSES - Não há conflito interesses.

\section{LICENÇA DE USO}

Os autores cedem à Motrivivência - ISSN 2175-8042 os direitos exclusivos de primeira publicação, com o trabalho simultaneamente licenciado sob a Licença Creative Commons Attribution Non-Comercial ShareAlike (CC BY-NC SA) 4.0 International. Esta licença permite que terceiros remixem, adaptem e criem a partir do trabalho publicado, desde que para fins não comerciais, atribuindo o devido crédito de autoria e publicação inicial neste periódico desde que adotem a mesma licença, compartilhar igual. Os autores têm autorização para assumir contratos adicionais separadamente, para distribuição não exclusiva da versão do trabalho publicada neste periódico (ex.: publicar em repositório institucional, em site pessoal, publicar uma tradução, ou 
como capítulo de livro), com reconhecimento de autoria e publicação inicial neste periódico, desde que para fins não comerciais e compartilhar com a mesma licença.

\section{PUBLISHER}

Universidade Federal de Santa Catarina. Programa de Pós-Graduação em Educação Física. LaboMídia - Laboratório e Observatório da Mídia Esportiva. Publicado no Portal de Periódicos

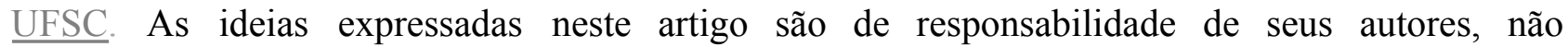
representando, necessariamente, a opinião dos editores ou da universidade.

\section{EDITORES}

Mauricio Roberto da Silva, Giovani De Lorenzi Pires, Rogério Santos Pereira.

\section{EDITOR DE SEÇÃO}

Bianca Poffo.

\section{REVISÃO DO MANUSCRITO E METADADOS}

João Caetano Prates Rocha; Keli Barreto.

\section{HISTÓRICO}

Recebido em: 25 de fevereiro de 2021.

Aprovado em: 05 de julho de 2021. 